\title{
Obstetric near miss events and maternal deaths in a tertiary care hospital
}

\author{
Vrinda Patil*, Vidya Kamath, Rathnamala M. Desai
}

Department of Obstetrics and Gynecology, SDM College of Medical Sciences and Hospital, Manjushree Nagar, Sattur, Dharwad, Karnataka, India

Received: 17 November 2017

Accepted: 18 December 2017

*Correspondence:

Dr. Vrinda Patil,

E-mail: drpatilvrinda@gmail.com

Copyright: () the author(s), publisher and licensee Medip Academy. This is an open-access article distributed under the terms of the Creative Commons Attribution Non-Commercial License, which permits unrestricted non-commercial use, distribution, and reproduction in any medium, provided the original work is properly cited.

\section{ABSTRACT}

Background: Maternal mortality is one of the important indicators of maternal health. Objectives of present study were to determine the frequency of maternal near miss, maternal near miss incidence ratio, maternal near miss to mortality ratio and mortality index and to study the risk factors associated with near miss events.

Methods: A retrospective analysis of severe maternal morbidity from January 2015 to December 2015 was studied. Data was collected from women with pregnancy related life-threatening complications, near miss cases and maternal deaths.

Results: The total number of deliveries were 5247. The numbers of maternal deaths were 12 . Maternal mortality ratio was 228 per one lakh deliveries. There were 5.3 near miss events for every 1 maternal death. The nature and course of near miss cases were analysed. Severe maternal odds ratio was 14.48 . Mortality index was $15.78 \%$. Maternal near miss incidence ratio was 12.19 .

Conclusions: Near Miss Mortality indicator is helpful in identifying the life-threatening conditions and thus aiming to prevent maternal mortality. Hypertensive disorders and its complications are the leading causes of near miss events. Sepsis is the main cause of maternal death.

Keywords: Live births, Maternal mortality rate, Maternal near miss

\section{INTRODUCTION}

Maternal mortality is one of the important indicators of maternal health. Reducing the maternal mortality by $75 \%$ has been the target of Millennium Development Goal 5, which was not met. Now there is Sustainable Development Goal (SDG 3) the target is to reduce the global maternal mortality ratio to less than 70 per one lakh live births by $2030 .{ }^{1,2}$ The standard indicator for measuring the maternal health is the Maternal Mortality Ratio(MMR) defined as the ratio of the number of maternal deaths per $1,00,000$ live births. ${ }^{3}$

In India there is a decline in MMR compared to 2010 statistics. Severe Acute Maternal Morbidity (SAMM) has been introduced to analyse the quality of the health care system, thus to improve the obstetric care. SAMM and Near Miss events are complimentary to MMR. ${ }^{4}$

Maternal near miss is defined as a woman who nearly died but survived a complication during pregnancy, childbirth or within 42 days of termination of pregnancy. ${ }^{4,5}$

If maternal near miss cases are more than the maternal deaths, they provide useful information on quality of health care. Potentially life-threatening conditions end up in near miss events. ${ }^{4}$ Some of these women end up in mortality, few of them narrowly escape death. Near miss 
cases and maternal deaths together are Severe Maternal Outcome (SMO).

There are three delays which have been identified to analyse the gaps in the management of obstetric emergencies leading to severe maternal complications and death. First delay is in seeking health care by the women due to lack of awareness of the need for care or failure to recognize the warning signals or lack of support of the family. ${ }^{6}$ Second delay is inaccessibility of the health care facility due to socioeconomic barriers or lack of transportation facilities. The third delay occurs in receiving adequate care at the facility system due to delay in diagnosis, decision making, deficiencies in medical facilities like availability of blood and blood products or intensive care unit, or lack of medical staff who are trained in management of obstetric emergencies. In developing countries like India $75 \%$ of women with obstetric complications are already in critical condition when they arrive at a tertiary care. Hence the medical staff at the peripheral health centres should be made aware of the danger signals and utilization of maternal near miss review done.

\section{METHODS}

A retrospective study of maternal near miss cases was done for a period of one year from January 2015 to December 2015 at SDM hospital Dharwad. Data was collected from women with potentially life threatening complications. Those who met the criteria for WHO 2009 maternal near miss were selected and studied. Ours is a tertiary care hospital with referral from primary health centres and private hospitals in the surrounding districts. We have 24 hours emergency obstetric care facilities with High Dependency Unit in the labour ward, Intensive Care Unit and 24 hour availability of blood and blood products.

WHO recommended three different criteria for identification of MNM patients. ${ }^{5}$ They are clinical, laboratory and management based criteria. Total numbers of live births were recorded. Potentially life threatening complications were studied. Risk factors leading to maternal near miss events based on WHO criteria were studied. The causes of maternal mortality analysed.

\section{Clinical criteria}

- Acute cyanosis

- Gasping

- Respiratory Rate $>40$ or $<6 /$ min

- Shock

- Oliguria (urine output $<30 \mathrm{ml} /$ hour for 4 hours) not responding to fluids or diuretics

- Loss of consciousness $\geq 12$ hours

- Clotting failure (absence of clotting from IV site after 7-10 mins)

- Uncontrollable fits

- Stroke
- Jaundice in the presence of pre-eclampsia

- Loss of consciousness and absence of pulse/heart beat

\section{Laboratory criteria}

- Acute thrombocytopenia $\leq 50,000$ platelets

- $\quad$ Bilirubin $\geq 6.0 \mathrm{mg} / \mathrm{dl}$

- $\quad$ Creatinine $\geq 3.5 \mathrm{mg} / \mathrm{dl}$

- Oxygen saturation $<90 \%$ for $>60$ minutes

\section{Management criteria}

- Transfusion of $\geq 5$ units of PRBCs

- Hysterectomy for postpartum haemorrhage or infection

- Dialysis for acute renal failure

- Intubation and ventilation for $>60 \mathrm{mins}$ not related to anaesthesia

- Use of continuous vasoactive drugs

\section{The following indices were}

SMOR-Severe maternal odds ratio, MMR-Maternal mortality ratio MNM: MMR-Maternal near miss to maternal mortality ratio, MI-Mortality index. ${ }^{7}$

- SMOR- Potentially life threatening conditions (MNM+MD) per 1000 LB.

- $\quad$ MMR-Number of maternal deaths per 1 lakh LB.

- MNM:MMR-Proportion of maternal near miss and maternal deaths, higher the ratio, better is the care.

- MI-Number of maternal deaths divided by the number of women with life threatening complications expressed as percentage (MD/MNM+MD). Lower index indicates better health care. ${ }^{1,4}$

- $\quad$ MNM incidence ratio-Number of maternal near miss cases per $1000 \mathrm{LB}(\mathrm{MNM} / 1000 \mathrm{LB})$. Increasing ratio denotes improvement in obstetric care. ${ }^{1}$

\section{RESULTS}

There were 5247 live births during the study period, maternal deaths were 12 and maternal near miss cases were 64.

There were 582 potentially life threatening conditions among 5247 live births (11.092\%). Among these $69.34 \%$ were severe pre eclampsia and its related conditions (eclampsia, abruption, HELLP syndrome). Haemorrhage (antepartum and postpartum) was seen in $23.88 \%$. Cardiac disease like mitral stenosis was seen in $7.04 \%$. Sepsis was seen in $1.03 \%$.

Prevalence of eclampsia was 6.67 per $1000 \mathrm{LB}$ in our study (35 in number). Only one patient has been included as SAMM, who had uncontrollable fits. WHO criteria for neurological dysfunction includes uncontrollable 
fits/status epilepticus, prolonged unconsciousness (lasting for $\geq 12$ hours)/coma and stroke.

Table 1: Potentially life-threatening complications.

\begin{tabular}{|lll|}
\hline Disease complication & $\begin{array}{l}\text { Number } \\
\text { (total 582) }\end{array}$ & $\%$ \\
\hline Severe pre-eclampsia & 317 & 54.4 \\
\hline Eclampsia & 35 & 6.01 \\
\hline Abruptio placenta & 40 & 6.87 \\
\hline Postpartum haemorrhage & 44 & 7.56 \\
\hline Ectopic pregnancy & 21 & 3.60 \\
\hline $\begin{array}{l}\text { Antepatrum haemorrhage } \\
\text { (placenta previa) }\end{array}$ & 45 & 7.73 \\
\hline Abortion with severe haemorrhage & 10 & 1.71 \\
\hline Cardiac disease with pregnancy & 41 & 7.04 \\
\hline Placenta accreta & 04 & 0.68 \\
\hline HELLP syndrome & 14 & 2.06 \\
\hline Rupture uterus & 03 & 0.51 \\
\hline Sepsis & 06 & 1.03 \\
\hline Dengue & 04 & 0.68 \\
\hline
\end{tabular}

Table 2: Near miss cases, clinical criteria.

\begin{tabular}{|c|c|c|}
\hline Clinical criteria & Number & $\%$ \\
\hline Eclampsia with uncontrolled fits & $01(35)$ & 2.85 \\
\hline Abruption with DIC & $03(40)$ & 7.5 \\
\hline $\begin{array}{l}\text { Severe pre-eclampsia, HELLP } \\
\text { with jaundice }\end{array}$ & $14(317)$ & 4.41 \\
\hline $\begin{array}{l}\text { Atonic PPH with massive } \\
\text { transfusion }\end{array}$ & $06(40)$ & 15 \\
\hline PPH with haemorrhagic shock- & $10(44)$ & 22.7 \\
\hline $\begin{array}{l}\text { Ruptured ectopic pregnancy with } \\
\text { haemorrhagic shock }\end{array}$ & $12(21)$ & 57.14 \\
\hline $\begin{array}{l}\text { Cardiac disease with atrial } \\
\text { fibrillation }\end{array}$ & $01(41)$ & 2.43 \\
\hline $\begin{array}{l}\text { Uterine inversion with } \\
\text { haemorrhagic shock }\end{array}$ & $01(2)$ & 50 \\
\hline $\begin{array}{l}\text { Rupture uterus with haemorrhagic } \\
\text { shock }\end{array}$ & $03(3)$ & 100 \\
\hline Severe pre-eclampsia with CVT & $02(317)$ & 0.63 \\
\hline Sepsis with septic shock & $06(11)$ & 54.5 \\
\hline
\end{tabular}

Hypertension and its complications are the leading causes of MNM cases (patient may fit into multiple criteria).

Table 3: Near miss cases, laboratory criteria.

\begin{tabular}{|l|l|}
\hline Laboratory based criteria & Number (total) \\
\hline Bilirubin $>6.0 \mathrm{mg} / \mathrm{dl}$ & $14(317)$ \\
\hline $\begin{array}{l}\text { Acute thrombocytopenia } \\
\text { (platelet count } \leq 50,000)\end{array}$ & $14(317)$ \\
\hline $\begin{array}{l}\text { Oxygen saturation }<90 \% \text { for }>60 \\
\text { minutes }\end{array}$ & $04(30)$ \\
\hline
\end{tabular}

Sepsis is the leading cause of maternal mortality followed by hypertension, haemorrhage and cardiac disease. Among 12 cases, 5 were with puerperal sepsis (41.67\%) 3 were due to haemorrhagic shock $(25 \%) 3$ were due to severe pre-eclampsia $(25 \%)$ and one case of cardiac disease in pregnancy $(8.34 \%)$.

Table 4: Near miss cases, management criteria.

\begin{tabular}{|ll|}
\hline Management based criteria & Number (Total) \\
\hline $\begin{array}{l}\text { Peripatrum hysterectomy (rupture } \\
\text { uterus-3, placenta accreta-3) }\end{array}$ & $06(6)$ \\
\hline ICU admissions & $57(582)$ \\
\hline $\begin{array}{l}\text { Intubation and ventilation for }>60 \\
\text { min not related to anaesthesia }\end{array}$ & $30(57)$ \\
\hline Dialysis for acute renal failure & $01(57)$ \\
\hline
\end{tabular}

The average age of women who died was 25.5 years. All the 12 cases were referred from nearby hospitals to our hospital in critical condition. Among them 5 were antenatal, 7 were referred after delivery due to jaundice, postpartum haemorrhage, sepsis, acute inversion of uterus, absence of urine output or acute renal failure. The antenatal cases were severe anaemia, pre eclampsia, HELLP syndrome, bronchopneumonia or rheumatic heart disease in congestive cardiac failure.

Table 5: Maternal deaths.

\begin{tabular}{|c|c|}
\hline Maternal complication & Cause of death \\
\hline Puerperal sepsis & Acute renal failure \\
\hline Puerperal sepsis & $\begin{array}{l}\text { ARDS, severe } \\
\text { bronchopneumonia }\end{array}$ \\
\hline $\begin{array}{l}\text { Uterine inversion with } \\
\text { severe anaemia }\end{array}$ & DIC, haemorrhagic shock \\
\hline $\begin{array}{l}\text { Severe pre-eclampsia, } \\
\text { thrombocytopenia with } \\
\text { bronchopneumonia }\end{array}$ & Septic shock \\
\hline $\begin{array}{l}\text { Traumatic PPH with } \\
\text { severe anaemia }\end{array}$ & $\begin{array}{l}\text { Haemorrhagic shock, } \\
\text { DIC }\end{array}$ \\
\hline $\begin{array}{l}\text { Severe pre-eclampsia } \\
\text { with severe Mitral } \\
\text { stenosis in CCF }\end{array}$ & $\begin{array}{l}\text { Cardiac arrest (secondary } \\
\text { to MV dysfunction), } \\
\text { bronchopneumonia, } \\
\text { septic shock }\end{array}$ \\
\hline $\begin{array}{l}\text { Severe pre-eclampsia } \\
\text { with HELLP syndrome }\end{array}$ & $\begin{array}{l}\text { Cardiopulmonary arrest } \\
\text { secondary to } \\
\text { haemorrhagic shock }\end{array}$ \\
\hline Puerperal sepsis & MODS \\
\hline Puerperal sepsis & Septic shock \\
\hline $\begin{array}{l}\text { Severe pre-eclampsia, } \\
\text { HELLP, severe anaemia }\end{array}$ & Pulmonary oedema \\
\hline $\begin{array}{l}\text { HELLP syndrome, } \\
\text { puerperal sepsis }\end{array}$ & $\begin{array}{l}\text { Acute kidney injury, } \\
\text { pulmonary embolism }\end{array}$ \\
\hline Severe pre-eclampsia & $\begin{array}{l}\text { Cardiopulmonary arrest, } \\
\text { pulmonary embolism }\end{array}$ \\
\hline
\end{tabular}

Among maternal death group, all the cases were unbooked, referred from other hospitals mainly the PHCs. Among the near miss group $60.9 \%$ of the cases were unbooked in our hospitals.

Among the potentially life threatening conditions $85.6 \%$ were antenatal women, $0.85 \%$ were postnatal and $0.51 \%$ 
were in early pregnancy and 4 cases were associated conditions like dengue.

Table 6: MNM indicators.

\begin{tabular}{|c|c|}
\hline SMOR & 14.48 \\
\hline $\begin{array}{l}\text { MNM incidence } \\
\text { ratio }\end{array}$ & 12.19 \\
\hline MMR & 228/1 LAKH LB \\
\hline MNM:MMR & $\begin{array}{l}5.3: 1 \text { (for every } 1 \text { maternal death } \\
\text { there are } 5.3 \text { maternal near misses) }\end{array}$ \\
\hline MI & $15.78 \%$ \\
\hline
\end{tabular}

\section{DISCUSSION}

WHO criteria for identification of obstetric near miss cases is helpful as it considers clinical, laboratory and management based criteria. Hence none of the cases are missed.

In a study by Purandare $\mathrm{C}$, total maternal near miss cases were $264(0.96 \%)$. Delay in seeking treatment was the main factor contributing to MNM. ${ }^{1}$

In a study by Madhavi, severe pre eclampsia and related conditions (eclampsia, abruption, HELLP syndrome) predominated the list of potentially life threatening conditions. Maternal near miss incidence ratio was 9.2 per 1000 live births. MNM to Mortality Ratio was 11:1. Mortality Index was $8.3 \%{ }^{2}$

Roopa PS et al in their study found 755 potentially lifethreatening cases, 131 near miss cases of the 7330 live births, MNM incidence ratio of 17.8 per 1000 LB.MNM to Mortality ratio was 5.6 to 1 . MI was $14.9 \%$. Among the MNM cases, haemorrhage was the leading cause followed by hypertension and then sepsis. Sepsis was the major cause of maternal mortality followed by haemorrhage, cardiac disease and hypertension. ${ }^{4}$ In a study by Purandare CN, it was found that $62.5 \%$ of MNM cases were in antenatal phase, $23.8 \%$ in post-natal phase. Haemorrhage was the major complication contributing to $46.9 \%$ of all cases. ${ }^{5}$

In a similar study done by Rathod $\mathrm{AD}$ et al, over a period of three years there were total of 161 near miss cases. MMR was $2.99 / 1000 \mathrm{LB}$, MNM to incidence ratio was 7.56/1000 LB. MI was 29. Haemorrhage was the leading cause of MNM, followed by anaemia. MNM to mortality ratio was 3.43:1 which means for every 3.4 women who survived a life-threatening complication, one woman died. ${ }^{6}$

In a study by Singh A et al, there were two maternal near miss for one maternal death. Hypertension and haemorrhage were the main cause of maternal near miss. ${ }^{8}$

Similar study by Chhabra P, the leading cause of MNM were haemorrhage, hypertension and sepsis. ${ }^{9}$ In a study by Kalra $\mathrm{P}$ et al, near miss incidence was 4.18/1000 LB. MMR was 202/1 lakh LB. MNM:Mortality was $2: 1 .^{10}$

In a study by Parmar N, MMR was 933/1 lakh LB. In a total of $1629 \mathrm{LB}, 46$ near miss cases were recorded.The ratio of MNM to maternal deaths was 2.6:1, MI was $28.1 \%{ }^{11}$ In the study done by Venkatesh $\mathrm{S}$, the prevalence of SAMM was $2.025 \% .^{12}$

The WHO criteria for pregnancy related life threatening conditions are part of strategy promoted by WHO for assessing and improving quality of maternal health care. ${ }^{13}$

The current MMR in India is $178 / 1$ lakh LB..${ }^{14}$ MMR in our study is 228/1lakh LB.

In present study MNM:MMR is 5.3:1 which means for every 5.3 women who survived a near miss complication, one woman died. MI in our study is 15.78. Lower index indicates better quality of health care. Few patients were brought to our hospital in a state of irreversible shock who could not be survived which highlights the delay in referral of women with danger symptoms and signs.

The health workers, ANMs, ASHA workers should be trained in recognizing the high risk patients and the warning symptoms and signs of pregnancy and hence early referral of these women to the nearest institutions. ${ }^{3}$ These women should be encouraged for a institutional delivery. These steps will go a long way in preventing maternal morbidity and mortality.

\section{CONCLUSION}

Maternal deaths are only the 'tip of the iceberg'. There are various risk factors leading to these deaths which have to be prevented. We have to identify the near miss cases and learn from them.

- Maternal near miss incidence ratio is $12.19 / 1000$ live births. Maternal mortality ratio is $228 / 1$ lakh live births. Maternal near miss to mortality ratio is 5.3 to 1.

- WHO criteria to identify the maternal near miss cases should be implemented in all peripheral health centres in rural India to identify the pregnancy related life-threatening conditions (e.g. severe preeclampsia and its related conditions, antepartum and postpartum haemorrhage) which helps in timely referral to tertiary hospitals. Our aim is in prevention of maternal mortality.

- Major causes of maternal near miss events and mortality are hypertension, haemorrhage, anaemia and sepsis, these can be prevented.

Funding: No funding sources

Conflict of interest: None declared

Ethical approval: The study was approved by the Institutional Ethics Committee 


\section{REFERENCES}

1. Purandare C, Bhardwaj A, Malhotra M, Bhushan H, Chhabra S, Shivkumar P. Maternal near- miss reviews: lessons from a pilot programme in India. BJOG: Int J Obstet Gynaecol. 2014 Sep 1;121(s4):105-11.

2. Madhavi Nacharaju SS, Kaul R, Reddy P. Maternal near miss: an experience in rural medical college. $\mathrm{J}$ Evol Med Dental Sci. 2014;3(56):12761-7.

3. Say L, Souza JP, Pattinson RC. WHO working group on maternal mortality and morbidity classifications. Maternal near miss-towards a standard tool for monitoring quality of maternal health care.Best Prac Res Clin Obstet Gynaecol. 2009;23:287-96.

4. PS R, Verma S, Rai L, Kumar P, Pai MV, Shetty J. "Near Miss" Obstetric Events and Maternal Deaths in a Tertiary Care Hospital: An Audit. J Pregnancy. 2013 Jun 26;2013.

5. Purandare CN. Maternal near miss review: a way forward. J Obstet Gynaecol India. 2103;63(4):213-5.

6. Rathod AD, Chavan RP, Bhagat V, Pajai S, Padmawar A, Thool P. Analysis of near-miss and maternal mortality at tertiary referral centre of rural India. J Obstet Gynecol India. 2016 Oct 1;66(1):295300.

7. Pattinson R, Say L, Souza JP, Broek NV, Rooney C. WHO maternal death and near miss classifications. Bull World Health Organ. 2009;87(10):734.

8. Abha S, Chandrashekhar S, Sonal D. Maternal near miss: a valuable contribution in maternal care. J Obstet Gynecol India. 2016 Oct 1;66(1):217-22.
9. Chhabra P, Guleria K, Saini NK, Anjur KT, Vaid NB. Pattern of severe maternal morbidity in a tertiary hospital of Delhi, India: a pilot study. Trop Doctor. 2008 Oct;38(4):201-4.

10. Kalra P, Kachhawaha CP. Obstetric near miss morbidity and maternal mortality in a tertiary care centre in Western Rajasthan. Indian J Public Health. 2014 Jan;58(30):199-201.

11. Parmar NT, Parmar AG, Mazumdar VS. Incidence of maternal "near-miss" events in a tertiary care hospital of Central Gujarat, India. J Obstet Gynecol India. 2016 Oct 1;66(1):315-20.

12. Venkatesh S, Ramkumar V, Sheela CN, Thomas A. Implementation of WHO Near-Miss Approach for Maternal Health at a Tertiary Care Hospital: An Audit. J Obstet Gynecol India. 2016 Aug $1 ; 66(4): 259-62$.

13. World Health Organization. Evaluating the quality of care for severe pregnancy complication: The WHO near miss approach for maternal health. Geneva: World Health Organisation; 2011.

14. William J, Suresh S, Jyotsna S, Manasa SY. Maternal Mortality in India: a review of trends and patterns.institute of economic growth. IEG. 2015;353. Available at www.iegindia.org>workpap>wp 353.

Cite this article as: Patil V, Kamath V, Desai RM. Obstetric near miss events and maternal deaths in a tertiary care hospital. Int J Reprod Contracept Obstet Gynecol 2018;7:519-23. 